\title{
Educação, território e tecnologias digitais: a experiência nas escolas das Ilhas Egadi (Itália)
}

\author{
Education, territory and digital technologies: experience in schools \\ of the Aegadian Islands (Italy)
}

\author{
Educación, el territorio y las tecnologías digitales: la experiencia \\ en las escuelas de las islas Egades (Italia)
}

\author{
IRACEMA MUNARIM* \\ ROGÉRIO SANTOS PEREIRA** \\ GILKA GIRARDELLO***
}

\begin{abstract}
RESUMO - Este artigo busca discutir a apropriação pedagógica de tecnologias digitais nas escolas das Ilhas Egadi, no sul da Itália, visitadas em 2012, durante o período de estágio sanduíche no exterior (Capes/PDSE). Nessas escolas, tendo em vista o contexto em que estão inseridos, alunos e professores se utilizam de tecnologias digitais para construir um processo de reconhecimento coletivo de demandas e de busca por soluções que articulem saberes locais e globais. Ao analisar essa conjuntura, compreende-se que romper com o isolamento é muito mais complexo do que colocar equipamentos digitais nas salas de aula. É preciso exercer o resgate da cultura local, tecer laços de pertença ao território, valorizar suas práticas e memórias, conectar a escola ao mundo e ancorá-la ao próprio território.
\end{abstract}

Palavras-chave - Tecnologias digitais. Cultura. Território. Escola.

ABSTRACT - This article discusses the pedagogical appropriation of digital technologies in schools of the Aegadian Islands in southern Italy, which were visited in 2012 during the "sandwich" doctoral fellowship abroad (Capes/PDSE). In these schools, considering the context in which they are inserted, students and teachers use digital technologies to construct a process of collective recognition of needs and a search for solutions that articulate local and global knowledge. By analyzing this situation, (can be?) understand that breaking with the isolation is much more complex than placing digital equipment in the classroom. It is necessary to revive local culture, weave ties of belonging to the territory, respect and emphasize its practices and memories, connect schools to the world and anchor them to their own territory.

Keywords - Digital technologies. Culture. Territory. School.

RESUMEN - Este artículo quiere analizar la apropiación pedagógica de las tecnologías digitales en las escuelas de las Islas Egades, en el sur de Italia, que fueron visitadas en 2012 durante el período de formación en el extranjero previsto por el curso de doctorado (Capes/PDSE). En estas escuelas, teniendo en cuenta el contexto en el que se insertan, estudiantes y profesores utilizan las tecnologías digitales para construir un proceso de reconocimiento colectivo de las demandas y de búsqueda de soluciones que combinen conocimientos locales y globales. Analizando esta situación, se entiende que romper el aislamiento es mucho más complejo que poner equipos digitales en las aulas. Es necesario rescatar la cultura local, tejer lazos de pertenencia al territorio, valorizar sus prácticas y memorias, conectar la escuela con el mundo y anclarlo a su territorio.

Palabras clave - Tecnologías digitales. Cultura. Territorio. Escuela.

* Doutora em Educação pela Universidade Federal de Santa Catarina (Florianópolis, SC, Brasil) e professora na Universidade Federal de Santa Catarina (Florianópolis, SC, Brasil). E-mail: <ira.munarim@gmail.com>.

**Doutor em Educação pela Universidade Federal de Santa Catarina (Florianópolis, SC, Brasil) e professor na Universidade Federal de Santa Catarina (Florianópolis, SC, Brasil).E-mail: <rogeriosantosp@gmail.com>.

*** Doutora em Ciências da Comunicação pela Universidade de São Paulo (São Paulo, SP, Brasil) e professora na Universidade Federal de Santa Catarina (Florianópolis, SC, Brasil).E-mail: < gilka@floripa.com.br>. 
Este $\operatorname{artigo~}^{1}$ busca discutir a apropriação pedagógica de tecnologias digitais nas escolas das Ilhas Egadi, no sul da Itália, visitadas em 2012, durante o período de estágio sanduíche no exterior (Capes/PDSE) ${ }^{2}$. Ao se pesquisar a inserção das tecnologias digitais nas escolas do campo no Brasil, encontrou-se nas escolas isoladas italianas um contexto que permitiu refletir sobre as dificuldades que se enfrentam em nosso país e conhecer caminhos de intervenção pedagógica que reforçam o papel social e político da escola nas comunidades. Essa aproximação entre dois cenários distintos e geograficamente distantes teve como inspiração o depoimento de uma professora italiana que narrou suas experiências pedagógicas com o uso de tecnologias em um evento acadêmico ${ }^{3}$. Este versava sobre o uso de dispositivos digitais móveis no campo da aprendizagem. A vontade de conhecer melhor o seu trabalho levou os autores ao arquipélago Egadi, formado por três ilhas que pertencem à região da Sicília, sul da Itália: Favignana, Marettimo e Levanzo.

A utilização do termo escolas isoladas ${ }^{4}$, para se referir às escolas de pequenas ilhas da Itália, destaca o fato de que, em decorrência da localização geográfica, estas vivem condições diferentes das existentes na maior parte das escolas daquele país: são escolas pequenas com número reduzido de crianças; há predominância de classes multisseriadas; existe dificuldade em contar com professores de disciplinas específicas e de realizar o transporte dos professores entre as ilhas e o continente; as escolas vivem a constante ameaça de fechamento (nas contas orçamentárias dos governos, custa menos transportar as crianças para um centro urbano do que manter a escola aberta). Já no Brasil, o isolamento é uma condição comum à maioria das escolas situadas no meio rural e também gerador de singularidades e dificuldades. Desse modo, a oportunidade que se teve de conhecer in loco uma realidade sociocultural e econômica diferente da brasileira inspira a fazer um exercício de aproximação e tradução intercultural (SANTOS, 2012) entre práticas pedagógicas que foram observadas no exterior (escolas isoladas) e cenários educativos do país (escolas do campo).

Como particularidade, as escolas de ilhas do sul da Itália elaboram estratégias que se apropriam política e pedagogicamente das tecnologias digitais para buscar romper com o isolamento cultural e geográfico a que estão submetidas. A opção pedagógica dessas escolas tem como objetivo promover o protagonismo dos estudantes no processo educativo de reconhecimento coletivo das demandas locais e a busca de suas soluções, bem como a construção coletiva de um sentimento de pertença à comunidade. Na luta pela manutenção e valorização de sua cultura, as escolas expressam o pedido de socorro e o grito de resistência de um arquipélago que pouco a pouco perde sua população em um fluxo migratório de famílias que avistam no continente a promessa de melhores oportunidades de trabalho e de estudo.

Ao colocar essa realidade no exterior em diálogo com o contexto brasileiro, novos questionamentos surgem sobre os papéis que as tecnologias digitais podem desempenhar em propostas de educação voltadas ao exercício da cidadania. Trata-se de um desafio metodológico ainda incipiente no Brasil que pode trazer importantes contribuições na articulação das escolas com os saberes locais e globais, na perspectiva da formação de sujeitos protagonistas em seus contextos e, acima de tudo, na afirmação de suas reivindicações. Em tempos de uma tão alardeada sociedade da informação, que atuaria num plano global, enfrenta-se o desafio posto por Jesús MartínBarbero $^{5}$ : é preciso romper com uma lógica de sociedade que desconhece seus próprios saberes. $\mathrm{O}$ conhecimento construído em redes de escala global precisa estar intimamente ligado a modos de agir localmente: "Pensar globalmente, agir localmente" (Think global, act local), como já ditava o slogan do ativismo ambientalista na conferência da ONU, no Rio, em 1992 (ECO 92).

No entanto, quando se transpõe a reflexão para a realidade brasileira, outros desafios surgem. De acordo com Boaventura de Souza Santos (2012), não existe justiça global sem justiça cognitiva global e, para que um outro projeto de sociedade se efetive numa convergência de saberes, é preciso pensar numa tradução intercultural. Para esse exercício, como mostra o autor, necessita-se conhecer profundamente a história de cada contexto sociocultural. Desse modo, é impossível fazer uma tradução intercultural de línguas que foram apagadas e de conhecimentos que foram suprimidos, marginalizados, invalidados durante séculos. Ainda para Boaventura de Souza Santos, não há tradução intercultural sem justiça histórica: "Tradução intercultural é uma tentativa de criar inteligibilidade entre diferentes saberes sem destruir a identidade de nenhum deles. Isto, obviamente, é um exercício difícil" (ibid., s.p.).

Para reforçar a importância das escolas situadas em contextos não urbanos, como é o caso das ilhas do sul da Itália e também das escolas do campo no Brasil, na constituição de laços entre população e território, buscouse aporte teórico em Bonnal, Cazella e Delgado (2012). Na perspectiva da reflexão sobre o desenvolvimento territorial sustentável, eles afirmam que a pluralidade de definições de território corresponde à diversidade das práticas de construção e de uso do território pelos atores sociais. Para além do conceito geográfico, que compreende território como "uma porção de espaço delimitado e qualificado por um caráter específico natural, cultural, político ou administrativo" (ibid, s.p.), definindo o que está dentro e fora dele por suas fronteiras, os autores ressaltam 
a importância do enfoque sociológico, do "território usado", como apresentado por Milton Santos ${ }^{6}$. Ele usa essa expressão para diferenciar o enfoque sociológico do enfoque geográfico padrão.

A ideia de "território usado" está associada às dimensões simbólicas como elemento central nas transformações de um território, nas suas configurações inacabadas, provisórias e mutáveis, reforçadas pela importância do papel de seus atores sociais.

Levando em consideração essas questões, a continuação deste artigo apresenta três momentos. O primeiro descreve o lugar onde se conheceram as experiências pedagógicas que hoje inspiram a fazer esta análise. É apresentada a ilha de Favignana, situada no arquipélago Egadi, em uma breve contextualização histórica e social que fornece subsídios para situar a importância da escola local e de suas práticas pedagógicas na afirmação daquele território, levando em conta as diversidades entre os dois contextos (Itália e Brasil)7 ${ }^{7}$. Em um segundo momento, são relatadas as práticas que buscam no aporte pedagógico das tecnologias digitais formas de romper com o isolamento em que essas ilhas italianas se encontram. Por fim, compartilha-se a busca por pontes (traduções) entre as práticas pedagógicas das ilhas e o "território" de uma educação do campo brasileira nas suas recentes aproximações com as tecnologias digitais.

\section{ISOLA-MENTOS: A ODISSEIA DE UM ARQUIPÉLAGO}

É com o azul translúcido das pequenas ondas que batem nas rochas de sua costa que as Ilhas Egadi abraçam os viajantes em um gesto de boas-vindas. Na maior e mais populosa das três pequenas ilhas que compõem o arquipélago mediterrâneo, a cor clara das paredes de pedra das casas reluz em contraste com o tom colorido das portas e janelas.

As estradas são de pedra ou de chão batido, com a rara exceção de um trecho de asfalto que conduz turistas e moradores às praias mais conhecidas da região. $\mathrm{O}$ centro é entrecortado por ruelas estreitas e sem calçadas, lembrando uma cidadela medieval. As casas de pedra mantêm, em sua maioria, a cor bege clara natural da pedra tufo, sem tinta e sem reboco, cuja espessura e estrutura porosa garantem o conforto térmico necessário tanto para os dias frios do rigoroso inverno quanto para o calor da temporada de verão.

O deslocamento até as Ilhas Egadi ajudou a dimensionar o desafio cotidiano da população em geral, e dos professores em particular, para transitar entre o arquipélogo e o continente (que na verdade é outra ilha, a Sicília). Em função do mal tempo que perdura durante toda a temporada de inverno e deixa o mar constantemente sem condições de navegação, foi preciso esperar a chegada da primavera para agendar a visita. A chegada à região se deu por via área, de Milão a Trapani, cidade siciliana onde um aeroporto militar foi aberto recentemente (no ano de 2003) ao tráfego civil, tornandose a principal porta de acesso à Sicília ocidental. Após o deslocamento de táxi até a região portuária, a viagem de Trapani até a ilha de Favignana segue sobre as águas a bordo de um aliscafo $^{8}$ em velocidade razoavelmente rápida ( 35 nós). Custa cerca de 8 euros e dura em média 45 minutos, sendo 30 minutos de trajeto até a primeira parada: a ilha de Levanzo, a menor do arquipélago.

De dentro da embarcação é possível observar a belíssima paisagem de Levanzo, que, junto às outras que formam o arquipélago, foi cenário de batalhas romanas ${ }^{9}$ e dos traçados das viagens fantásticas de Ulisses, o Odisseu. Embora sejam teses levantadas por historiadores e amantes da literatura, narrativas como essas ajudam a criar uma atmosfera imaginária das ilhas Egadi tais quais as cidades invisíveis de Calvino (2010) - imaginação e realidade se confundem; além de indissociáveis, ambas são indispensáveis à compreensão das ilhas. Levanzo, a possível ilha dos Ciclopes narrada em trechos da Odisseia, é a menor do arquipélago. De beleza paradisíaca e quase toda montanhosa, ela é cortada por uma única rua. Suas casas de pedra, brancas e amontoadas, cujas vistas das janelas são pintadas de azul, convidam o passante a contemplá-las. Entre a sua população, cada vez mais reduzida, quase não há mais crianças. Talvez por isso, do aliscafo avista-se uma vila bela e quase deserta.

O destino final, Favignana, assim como as outras ilhas Egadi, atualmente dependem predominantemente de um turismo sazonal para sobreviver. Os tempos áureos do desenvolvimento local deram lugar à especulação turística e imobiliária. Durante séculos, a ilha teve como suas principais atividades econômicas a extração de tufo (calcarenito - tipo de rocha arenítica) e a pesca de atum.

A extração das rochas deixou marcas em Favignana. Grandes pedreiras formam cavernas, galerias e poços cujas paredes guardam o formato anguloso dos blocos de pedra dali retirados. Com o esgotamento da extração do mineral, as impressionantes pedreiras desativadas transformaram-se também em atração turística da região, juntando-se ao mar cristalino, à peculiar arquitetura pétrea das simples casas que formam o vilarejo, aos palacetes e monumentos de outrora, à saborosa culinária siciliana, ao carisma e à simpatia da população local.

Além do trabalho nas pedreiras, a ilha também viveu tempos prósperos com a pesca do atum. Tão precioso para a economia local, hoje o peixe faz parte das narrativas dos antigos moradores que relembram saudosos os tempos de fartura proporcionados pela abundância da pesca marítima. Favignana já foi o maior polo pesqueiro de 
atum do mundo, espécie cada vez mais rara nos oceanos. A atividade com o atum nos mares do arquipélago de Egadi, apesar de sazonal, era extremamente elaborada e lucrativa, indo da pesca à produção industrial de conservas enlatadas. Do início da primavera, no mês de abril, aos primeiros dias de junho, a pesca se valia do período de reprodução da espécie, momento em que cardumes se aproximavam da costa siciliana ocidental. O ritual da pesca era um momento único, ritmado pelos cantos dos trabalhadores sobre seus barcos. Cantos solenes, de alegria e de reza ${ }^{10}$.

Com a primeira guerra mundial e com a crise econômica que se instituiu na Itália, deu-se início à queda de um grande império pesqueiro. Na década de 1970, a fábrica que processava o atum foi definitivamente fechada, deixando centenas de famílias desamparadas. A progressiva escassez tornou a pesca cada vez mais rara, e a última pesca de atum em Favignana foi registrada no ano de 2007. Em busca da preservação da memória local, a antiga fábrica desativada tornou-se patrimônio histórico da região da Sicília, nos anos 1990, e, no ano de 2009, foi transformada em museu ${ }^{11}$.

Entre os moradores das Ilhas Egadi, circulam as narrativas de tempos prósperos que ficaram na memória coletiva daquelas comunidades. Se antes a pesca era a principal atividade econômica da região, hoje predominam o turismo e a especulação imobiliária de investidores estrangeiros. Se antes havia ofertas de emprego, hoje os moradores precisam se deslocar ao continente com suas famílias à procura de trabalho. A vida das mulheres que habitam a ilha é outro fator que merece ser destacado na decisão pela partida das famílias ao continente. Numa pequena comunidade em que perdura uma estrutura familiar, onde os homens saem para trabalhar e as mulheres se ocupam dos afazeres domésticos, a migração tem sido uma opção, ainda que velada, de busca por valorização do universo feminino diante da resistência a mudanças numa cultura tradicionalmente patriarcal. Para muitas mulheres, a cidade é uma promessa de outra inserção na sociedade. Hoje, os habitantes das ilhas são em sua maioria idosos, que contam e recontam as histórias de um arquipélago num tempo passado repleto de crianças brincando nas ruas e praças, escolas cheias, muito artesanato e pesca. Se antes as escolas eram independentes, hoje elas perderam a autonomia, respondendo a uma coordenação centralizada no continente. E, se um dia elas possuíam muitos alunos, hoje lutam para não ter de fechar as portas por falta de crianças. Assim como no Brasil, onde se vive historicamente a contenção de gastos nas políticas educacionais, a situação de crise no continente europeu tem se refletido fortemente no corte de verbas públicas para a educação na Itália. Se no Brasil encontramse dirigentes políticos que preferem colocar ônibus à disposição das crianças para que estudem na cidade em vez de oferecer-lhes uma escola próxima de suas casas e dentro de seus contextos de vida, na Europa, a situação já estabelecida de oferecimento do ensino qualificado para todas as crianças passa atualmente por transformações e eventuais declínios nas políticas de educação.

As mudanças pelas quais a Europa passou, a partir do século XIX, como apresentado por Raymond Williams, tiveram reflexos significativos também nas atividades pesqueiras das ilhas Egadi. Em seu livro Ocampo e a cidade, Williams (1989) afirma que o surgimento do capitalismo não criou uma situação nova, mas reforçou algo que antes já existia. A exploração do trabalho, o desrespeito a outros seres humanos, o feudalismo, os conflitos, a tributação e a lei da espada não são recentes. Tendo como referência a perspectiva inglesa, o autor ressalta a importância de se pensar a partir de uma época sem paralelo histórico em termos das transformações campo/cidade: a Revolução Industrial, que acabou por cunhar o capitalismo agrário e o desaparecimento do campesinato tradicional. Nas Ilhas Egadi, apesar de o processo produtivo ter passado por grandes transformações, migrando da pesca artesanal para a constituição de uma produção fabril de conservas, o poder foi mantido em poucas mãos.

Problematizar, a partir do exemplo das Ilhas Egadi, o contexto de transformações na sociedade europeia pode ser um caminho para melhor se compreender a especificidade dos processos de constituição e transformação da sociedade brasileira. Ao se buscar um paralelo com outra realidade, podem-se identificar, além das semelhanças entre os dois contextos (escolas do campo e escolas de ilhas), as diferenças entre o Brasil e a Itália. E estas podem nos ajudar a refletir sobre as perspectivas das escolas do campo em nosso país.

Uma dessas diferenças diz respeito à contextualização de escolas isoladas e escolas do campo nas duas realidades. O contexto de isolamento de povos do campo, como o existente no Brasil, não possui correlação direta com a Itália e com os demais países da Europa Ocidental. Carrière e Cazella (2006), a partir do contexto rural francês, revelam que as formulações teóricas pioneiras sobre agricultura, campo, território e desenvolvimento territorial sustentável partem de uma realidade histórica diferente e com expressivos indicadores de desenvolvimento que ainda não se alcançou no Brasil. Não se pode negar queexistam ainda neste país latino-americano carências no meio rural a serem supridas e necessidades básicas a serem atendidas para sobrevivência digna da população. Dentre o grande número de situações precárias encontradas no Brasil, descrevem-se aqui cenários retratados em um programa da televisão aberta que escolheu como pauta a maior seca dos últimos 50 anos, afetando o Nordeste brasileiro no ano de 2013. 
O programa Profissão Repórter (GLOBO, 22/05/ 2013) ${ }^{12}$ abordou os problemas enfrentados por centenas de agricultores nordestinos que haviam contraído dívidas pelo menos cinco anos antes para investir em plantações e criação de gado. O empréstimo no Banco do Nordeste possibilitou que comprassem ração, sementes e material para fazer cercas. Mas, com a seca, eles perderam tudo: dos rebanhos de gados às pequenas plantações. Os empréstimos, que variavam entre 5 mil e 20 mil reais para cada um, haviam se convertido em dívidas com valores mínimos na casa dos 100 mil reais. A preocupação de um agricultor entrevistado e que não sabia que deveria pagar seu empréstimo no prazo de três dias - ele não tinha acesso aos jornais para ler as notificações oficiais e ainda era analfabeto - não era apenas a penhora de seus poucos bens, mas a maneira como conseguiria comida para sua filha no final de semana.

Outro exemplo citado no mesmo programa: dezenas de caminhões pipa retiram água diariamente do Rio São Francisco para distribuí-la a uma comunidade do estado vizinho, o Piauí. Essa água, imprópria para beber, é vendida a 2 reais o galão e é usada pela população para a preparação de alimentos. A cozinha de uma das entrevistadas não tem torneira porque a cidade ainda não tem água encanada.

O mesmo caminhão que leva água para a comunidade faz entregas para os órgãos da prefeitura. Os entrevistados responsáveis afirmam que a água é para limpeza, para lavar chão e carros. Mas esta é a mesma que chega às escolas e é a única que as crianças têm disponível para matar a sede durante o período de aulas. Enquanto isso, professores e servidores bebem de um galão de água mineral, o que, segundo o diretor da escola que dá entrevista (enquanto bebe da sua água potável), é "constrangedor", visto que as crianças consomem a água imprópria. $\mathrm{O}$ prefeito da cidade afirma que sabe da péssima qualidade, mas diz que não adianta oferecer água potável na escola porque as crianças, ao chegarem a suas casas, irão beber a água contaminada.

Ainda mais dificultada é a situação de quem mora nas zonas rurais, como do estado do Piauí, aonde não chegam caminhões pipa e ter água encanada não passa de um sonho distante. As dezenas de quilômetros que precisam ser transpostos diariamente para buscar água nas raras fontes que resistem à seca, como as demonstradas no programa de TV, tornam a vida ainda mais difícil.

Já no meio rural de um país como a Itália, em virtude da ampla rede rodoviária e ferroviária, e das menores distâncias quando comparadas a um país de dimensões continentais como o Brasil, os agricultores possuem trânsito facilitado entre suas propriedades e os centros urbanos, além de água e esgoto tratado, luz elétrica e acesso à saúde e à educação. Enquanto no Brasil enfrentam-se sérios problemas com as desigualdades de todo tipo, um dos maiores desafios da Europa atual é manter a equidade campo-cidade, especialmente porque é nas cidades que as diferenças socioeconômicas da população se tornam mais visíveis - crise econômica e aumento das taxas de desemprego; imigrantes, suas culturas e línguas diferentes, etc. (CAZELLA, 2008).

Esses breves exemplos ajudam a manter a atenção aos riscos de uma transposição direta entre os contextos europeu e brasileiro. Ao se lidar com propostas de tradução intercultural e buscar aproximações entre as escolas de isoladas e as escolas do campo, precisa-se considerar que ainda não foram superadas questões essenciais à sobrevivência, como a falta de água, de alimento, de educação, de saúde, de transporte, de dignidade. Assim, ao deslocar o foco das comparações entre duas realidades muito diversas para construir traduções entre elas, procurou-se identificar o que se pode aprender com as experiências do outro: o que, então, pode-se aprender com o cenário apresentado no isolamento das ilhas do sul da Itália e traduzir para o contexto educativo brasileiro?

Como acontece no Brasil, a situação atual de crise na Itália, mais especificamente no sul do país, tem impulsionado em seus moradores a busca por soluções para os problemas nos centros urbanos, onde tradicionalmente ficam concentradas as oportunidades de trabalho e estudos. Na busca por melhores condições de vida, os moradores do arquipélago de Egadi abandonam hoje as suas ilhas. Se um território perde cada vez mais seus habitantes, o patrimônio cultural e natural local fica à mercê de investimentos corporativos voltados à exploração turística e imobiliária. Se as ilhas ficam repletas de turistas durante a temporada de calor (julho a setembro), no resto do ano ficam vazias, sofrendo as consequências de uma lógica de mercado que não valoriza a cultura local sequer durante os meses de maior lucro financeiro. E, se a população da ilha vai embora, obrigada a ceder a um jogo de forças de interesses globais em detrimento dos saberes locais, as escolas perdem seus alunos - que vão embora das ilhas com suas famílias atrás da promessa de melhores condições de vida.

Essa dualidade em relação ao local, expressa pelos próprios moradores que o veem ora como paraíso, ora como subsistência, reforça uma dicotomia questionável entre campo e cidade, já que um não pode ser definido sem o outro. Para o mercado turístico, prevalece nas ilhas um estilo de modernização (resorts, conjuntos residenciais de luxo, pacotes de viagem) que é atrelado, curiosamente, às tradições que esse mesmo mercado descaracteriza, estereotipa, reifica, operando mediante lógicas de valor e de rentabilidade.

As turmas das poucas escolas locais estão cada vez mais reduzidas. Algumas delas possuíam em 2012 apenas 
dois a três alunos por classe multisseriada/heterogênea ${ }^{13}$. A condição de trabalho oferecida aos professores também não auxilia a valorização das escolas das ilhas. Como os professores não fazem parte das comunidades locais, muitas vezes são substitutos ou iniciantes na carreira os que se dispõem a fazer o longo trajeto entre a casa no continente e o trabalho nas ilhas. Como não é economicamente viável fazer esse deslocamento diariamente, eles permanecem de segunda a sexta-feira à disposição das escolas, retornando para suas casas e famílias somente aos finais de semana, embora muitas vezes, por questões meteorológicas, os professores sejam obrigados a permanecer nas ilhas, nos dias de descanso. Há uma grande rotatividade dos professores, que se transferem para escolas no continente diante da primeira oportunidade. Os docentes, além do deslocamento, precisam custear com seus próprios salários a habitação semanal na ilha, o que desencoraja a permanência de educadores fixos que possam dar continuidade às propostas pedagógicas ano após ano.

Como, então, manter um ensino qualificado para uma turma tão pequena, se os professores são em número reduzido, o que não permite nem ao menos a oferta de todas as disciplinas obrigatórias no currículo? Ampliando o deslocamento semanal dos professores do continente até as ilhas, à mercê das condições que frequentemente impedem o trânsito marítimo? Ou levando as crianças até uma escola no continente, separando-as de suas famílias e de seu território? Ambas as possibilidades apresentam problemas: o Estado não pode separar a criança do seio familiar, nem financiar, de acordo com o discurso de contenção de gastos públicos, a ida de muitos professores para atender a um número muito reduzido de alunos. Além disso, com as atuais condições de trabalho e remuneração oferecida aos professores, poucos são os que se dispõem a assumir o compromisso com as escolas das ilhas. Desse modo, vão-se as crianças, os jovens e adultos em idade produtiva, ficam os idosos e suas memórias.

Outra questão latente nas escolas das ilhas é o número reduzido de alunos. Duas crianças numa ilha não formam uma classe. Precisam de trocas, de confrontos, de desafios, de encontros com seus pares. E embora sejam só dois ou três alunos por classe, é obrigação do Estado oferecer ensino regular a essas crianças e jovens. Porém, mesmo vencendo-se a barreira da regularidade do ensino, o reconhecimento da qualidade das escolas das ilhas - legitimadas assim tanto diante das famílias quanto do Estado - é fundamental para a sobrevivência da rede de ensino local. E, tendo em vista o êxodo impulsionado pela busca de melhores condições de estudo e trabalho, é também essencial para a sobrevivência da própria comunidade. Apenas assim, as famílias sentemse encorajadas a permanecer nas ilhas, enxergando ali - e não apenas além-mar - perspectivas para a formação de suas crianças em escolas que pensam uma educação de qualidade, ou seja, igualitária e cidadã. Na ilha de Levanzo, por exemplo, todas as 10 crianças com idade entre 11 e 13 anos que lá habitavam e estudavam em 2012 deveriam se transferir com suas famílias, no começo do ano letivo de 2013, para Trapani, cidade mais próxima do continente, na região da Sicília, para cursar a Scuola Superiore (com duração de três anos), nível de ensino não oferecido na ilha.

Partindo da realidade das pequenas escolas de ilhas e de montanha italianas, Pier Cesare Rivoltella (2013) ${ }^{14}$ ressalta que, mesmo que seja considerado caro manter essas instituições a partir da lógica econômica mundial - o que tem provocado o desaparecimento de muitas escolas públicas de pequeno porte tanto na Itália quanto no Brasil -, refletir sobre escolas de contextos não urbanos é também uma oportunidade importante para discutir as perspectivas das políticas educativas em geral. Para Rivoltella, do ponto de vista social, é preciso considerar os graves problemas que são provocados quando são fechadas as portas dessas instituições. Como se viu no papel exercido pelas escolas nas comunidades das ilhas Egadi, Rivoltella demonstra que o empobrecimento de oportunidades num território resulta no seu abandono pelos jovens, que se transferem antecipadamente para as cidades. Do ponto de vista didático, o autor reforça, assim como Rui Canário (2000), que as escolas pluriclasse (comuns nesses contextos), "podem ser vistas como uma necessidade, mas também como uma oportunidade", já que "o professor é naturalmente levado a experimentar metodologias e técnicas que em uma aula tradicional não conseguem espaço" (RIVOLTELLA, 2013, s.p, tradução dos autores). Ele cita como exemplo o caso das didáticas tutoriais ${ }^{15}$, trabalhos em pequenos grupos, aprendizagem entre pares (peer learning) e ensino recíproco (reciprocal teaching). Nesse sentido, Rivoltella sintetiza: “A coisa interessante é que nestas situações, a precariedade se transforma em riqueza e a classe se transforma, com muito mais facilidade, em laboratório de inovações. Isso permite apresentar aos pais a escola da pequena comunidade (piccolo plesso) como uma oportunidade e não como um improviso" (ibid.).

Alguns anos atrás, foi a partir da iniciativa local que os professores fixos das escolas, moradores das ilhas Egadi, conseguiram, utilizando o uso pedagógico das mídias e o uso de ferramentas de Educação a Distância $(\mathrm{EaD})$, proporcionar a esse pequeno grupo de alunos um projeto educativo cuja qualidade e relevância substituíram a necessidade que as famílias possuíam de se mudar para o continente em busca de uma melhor educação para os seus filhos. Como os professores não chegavam às escolas, as crianças passaram a ir até os professores com o uso 
de internet via satélite e ferramentas de teleconferência. Desse modo, as crianças das ilhas puderam acompanhar em tempo real as aulas de disciplinas específicas que não eram oferecidas em suas escolas. E interagir com seus pares a distância, compartilhando a sala de aula com alunos de escolas parceiras localizadas em outras regiões da Itália. Além das câmeras e monitores, que permitem que os alunos vejam e sejam vistos em ambas as escolas (ilhas e continente), as salas de aula contam ainda com uma lousa digital cujo uso é compartilhado também em tempo real. Assim, uma mesma atividade pode ser feita na lousa de modo colaborativo entre crianças das diferentes escolas. Como exemplo, um texto que é escrito na lousa da escola de uma das ilhas é visto e pode ser também editado na lousa da escola do continente.

Embora o primeiro projeto de interação entre escolas das ilhas entre si, e das ilhas com o continente, batizado de Marinando, tenha vivido seus dias de plena realização, no ano de 2007, os desafios ainda são muitos ${ }^{16}$. A política de austeridade, assumida a partir de 2008 para combater a crise econômica europeia, fez com que os cortes de verbas atingissem duramente a educação, acarretando retrocessos na realização do projeto. Mas, mesmo com as dificuldades de financiamento, as tecnologias digitais e as mídias continuam a ser usadas pedagogicamente para legitimar as escolas das ilhas, abrindo as escolas ao mundo ao mesmo tempo em que buscam reforçar os saberes e contextos locais. Mais do que proporcionar uma educação às crianças considerada de qualidade, projetos que resgatam a memória local, envolvendo criação e veiculação das produções dos alunos que habitam as ilhas, tornam a escola um lugar especial de experimentação didática e inovação. Assim, a apropriação e o uso das tecnologias digitais têm sido cada vez mais valiosos no empoderamento da população local. Além do já citado estímulo para que as famílias permaneçam nas ilhas, a veiculação das próprias produções midiáticas pela internet é hoje um caminho curto e economicamente viável para reforçar a cultura local e atravessar fronteiras geográficas, de discursos, de pensamentos. É um grito de socorro audível ao resto do mundo, mas também um canto que celebra e compartilha a própria existência. Em um contexto de isolamento tanto geográfico quanto econômico, as escolas foram transformadas com o uso das tecnologias digitais. amTornaram-se referências culturais das comunidades e ajudaram a reconstruir as relações de pertencimento e identidade da população local.

As escolas transformaram-se em ponto de referência da população das ilhas como instrumento de voz ativa ao levantar a bandeira pelo não esvaziamento da população local e pela preservação da identidade da ilha. Ocupam hoje um lugar central na valorização dos saberes locais, fortalecendo os laços entre população e território. Ao tentarem romper o isolamento cultural e geográfico, as propostas pedagógicas das escolas visitadas proporcionaram movimentos de abertura, de criação de pontes entre as ilhas e o continente. Mostraram o que representa o isolamento de uma população e quais perspectivas a educação pode propor para auxiliar a comunidade a realizar novas travessias. Um dos aprendizados que se podem ter com essa experiência está relacionado à ligação entre identidade e território, muito relacionada com as questões de quem se é, o que se faz, onde se mora, do que se brinca.

A partir de uma estratégia de valorização do território, escola e comunidade se apropriaram das mídias como ferramentas de auxílio na construção de sua historiografia. De um lado, o museu de uma antiga fábrica de conservas de atum, patrimônio do município de Favignana, valoriza as narrativas de antigos moradores. A exposição de relatos históricos de quem vivenciou o passado da ilha, em memórias gravadas e acessíveis à comunidade e aos turistas, através de hologramas, possibilita uma presença corporificada de quem já não pode mais estar presente. Existe nos projetos do museu uma ênfase muito grande na busca por essa reconstrução que passa muitas vezes por um resgate das práticas corporais associadas ao trabalho, mas também aos momentos de lazer. De outro lado, a escola se dispõe a fazer registros e produções midiáticas com seus alunos a partir das investigações sobre as histórias do lugar. Dentre as práticas pedagógicas que se teve a oportunidade de acompanhar durante a estada nas ilhas, foram selecionadas algumas que sugerem possibilidades metodológicas para o uso de tecnologias em contextos educativos em geral e nas escolas do campo em particular.

O primeiro exemplo parte da experiência de uma turma de alunos ${ }^{17}$ que visitou uma antiga prisão de perseguidos políticos do regime fascista de Mussolini, situada em Favignana. Na primeira e única visita que fizeram ao local, que é fechado para visitações públicas, as crianças se surpreenderam ao encontrar, dentro do cárcere, salas estreitas e sem tetos onde inimigos políticos eram depositados à mercê das intempéries. No chão e nas paredes, os alunos encontraram registros escritos e desenhos que corporificavam a presença de quem ali foi forçado a entrar e muito provavelmente não saiu com vida. Eram marcas profundas de escrituras, ação direta das mãos contra a pedra: protestos, denúncias, declarações de amor, tristeza, saudade. As fotografias feitas pelas crianças com as câmeras de celular e tablets tornaram-se parte de um projeto pedagógico mais amplo, que se propôs a estudar a razão de ser desse presídio e a história (apagada e ocultada) das pessoas que nele sofreram as condições desumanas estabelecidas por um poder ditatorial. Os registros fotográficos foram cuidadosamente colocados pelos alunos em uma plataforma que simula um museu 
virtual ${ }^{18}$ onde os movimentos de um avatar proporcionam a sensação de espacialidade que simula um museu físico. Nessa proposta, cabe observar a agência e participação das crianças, que por meio da tecnologia registraram seu olhar, seu enquadramento, suas opções do que focalizar e do que excluir em cada foto. E que, com um minucioso trabalho de pesquisa e criação, recontaram e deram dignidade às histórias encontradas na prisão. Em casos como esse, as tecnologias se mostram valiosas e talvez até mesmo essenciais para o potencial crítico e emancipatório de um projeto educativo.

O Brasil também passou por um regime ditatorial violento, cujas marcas estão registradas até hoje, nos corpos, afetos e memórias das pessoas que sobreviveram às perseguições. Trata-se de uma triste lembrança que precisa se manter viva para que situações similares não se repitam em nossa sociedade. Esse é um tema, entre tantos outros, que pode ser trabalhado, com o auxílio das tecnologias, tendo os alunos como protagonistas do processo educativo.

Outro exemplo é a proposta de criação de um livro digital (e-book) coletivo, com a participação de todos os alunos de uma mesma classe multisseriada ${ }^{19}$. Nas escolas das Ilhas Egadi, os alunos se dedicavam a criar livros digitais com temas variados. Construído de modo colaborativo, o tipo e a complexidade da participação variavam de acordo com a faixa etária. Durante a visita à escola, a turma de educandos com faixa etária entre 11 e 12 anos desenvolvia um projeto de entrevistas com a comunidade da ilha para registrar a história da pesca do atum, tão importante na cultura local. Das entrevistas e visitas ao museu surgiram produções audiovisuais, que podiam ser autônomas, compondo o museu virtual, ou servir de ilustração no livro que eles estavam construindo. Outras ilustrações da obra eram feitas através de fotos, desenhos, documentos originais e criações artísticas variadas que poderiam ser digitalizadas. O registro de voz (podcasting), além de entrar como narrativa do livro (audiobook), compõe ainda outras propostas pedagógicas, como a sensibilização auditiva e o trabalho com diferentes sotaques e dialetos. ${ }^{20}$

Num contexto brasileiro - e fala-se aqui em escolas que possuam no mínimo o acesso a um computador ou a um equipamento para registro de vídeo, como um celular ou uma câmera fotográfica digital -, pode-se pensar em estratégias que instiguem os estudantes a refletir sobre a história e sobre a cultura do lugar onde nasceram e estão crescendo. Em possibilidades de aulas com temáticas escolhidas coletivamente, que contribuam para a formação estética e crítica dos alunos, da mesma forma com que as crianças de Favignana usam as tecnologias digitais para buscar a história local, o resgate da cotidianidade do lugar passa também pelo lúdico, pela festa, pelo esporte, pelos modos de lidar com o corpo. Tudo isso, sem perder de vista a importância de conhecer e fortalecer as lutas dos povos do campo por território, terra, teto, respeito, dignidade. Pela legitimação dos "outros" saberes, por um outro projeto de campo.

Ao conectar as escolas das Ilhas Egadi ao mundo e ancorá-las ao próprio território, elas nos ensinam a construir com as crianças novos sentidos para as relações entre o global e local. O exercício de alteridade que os encontros com outras pessoas e outras realidades pode proporcionar, por exemplo, é um dos princípios que orientaram o projeto Brazil Calls Egadi ${ }^{21}$, desenvolvido entre duas escolas brasileiras - uma em Florianópolis e outra em Rio do Sul - e as escolas das Ilhas Egadi. Estas, formando pequeno arquipélago localizado na Sicília, no sul da Itália. Iniciado no segundo semestre de 2013 e ainda em andamento, o projeto faz uso de diferentes linguagens e plataformas digitais para que crianças brasileiras e italianas que cursam, aqui e lá, o 5o ano do ensino fundamental, possam tanto falar delas próprias e do lugar onde vivem quanto escutar de outras crianças o que é "ser criança" em um contexto social, cultural, linguístico, geográfico diverso.

Experiências pedagógicas como as apresentadas neste texto se dão buscando diversas formas de linguagens e diferentes graus de complexidade. Por exemplo, por meio do desenho, da fotografia, do vídeo, da oralidade, dos jogos de representação, das pesquisas bibliográficas, das entrevistas - todas estratégias valiosas também quando se utilizam tecnologias digitais. A partir do uso dessas tecnologias, são tecidas aproximações entre escola e comunidade, entre crianças e adultos, entre alunos e professores, entre jovens e idosos, entre crianças menores e crianças maiores. Romper com o isolamento é um processo muito mais complexo do que instalar um equipamento para aulas a distância. É preciso exercer a reflexão crítica, a valorização da cultura local, das memórias e das lutas do presente que ajudam a tecer laços de pertença ao território. Promover rupturas, atribuir novos sentidos às tecnologias digitais. Questionar seus modos de produção, seus usos, suas relações com o mercado. É preciso, com práticas como essas, suscitar reflexões entre crianças e jovens, para que se reconheçam como atores sociais e possam se assumir como sujeitos de suas práticas, sentindo-se encorajados a participar ativamente das decisões que envolvam suas vidas e comunidades.

A aproximação com experiências pioneiras no exterior mostrou-se um passo para conhecer processos de apropriação das tecnologias digitais que podem auxiliar no fortalecimento de uma educação crítica voltada ao exercício da cidadania e à valorização do território e dos saberes locais. E a experiência das escolas das Ilhas 
Egadi com o uso de tecnologias digitais, em uma tradução intercultural, pode ajudar a buscar estratégias para legitimar as escolas do campo brasileiras, abrindo espaço para currículos apoiados na realidade de seus professores e estudantes, nos tempos e saberes próprios da vida que se leva no campo.

\section{REFERÊNCIAS}

CALVINO, Italo. Le città invisibili. Milano: Mondadori, 2010.

CANÁRIO, Rui. A escola no mundo rural: contributos para a construção de um objecto de estudo. Educação, Sociedade \& Culturas, n. 14, p. 121-139, 2000.

CARRIÈRE, J. P.; CAZELLA, Ademir Antonio. Abordagem introdutória ao conceito de desenvolvimento territorial. Eisforia, Florianópolis, v. 1, n. 1, p. 23-46, 2006.

CAZELLA, Ademir Antonio. As bases sociopolíticas do desenvolvimento territorial: uma análise a partir da experiência francesa. Redes, v. 13, n. 1, p. 5-27, 2008.

BONNAL, Philippe.; CAZELLA, Ademir Antonio; DELGADO, Nelson Giordano. Contribuições ao estudo do desenvolvimento territorial rural: reflexões metodológicas a partir do caso brasileiro. Biblio 3W - Revista Bibliográfica de Geografía y Ciencias Sociales, v. 17, n. 1002, 2012.

ENTREVISTA COM JESÚS MARTÍN BARBERO. Seminário Internacional sobre Diversidade Cultural). Disponível em: $<$ https://www.youtube.com/watch?v=U7jo4G4_quQ $>$. Acesso em: 16 abr. 2013.

GLOBO, Rede. Profissão Repórter. [S.l: s.n.]. 2013.

IL MUSEO - EX STABILIMENTO FLORIO A FAVIGNANA. Disponível em: <http://www.egadivacanze.it/informazioni/ favignana/il-museo-stabilimento-florio.html $>$. Acesso em: 22 maio 2013.

MUNARIM, Iracema. Tecnologias digitais nas escolas do campo: contextos, desafios e possibilidades. 2014. 183 f. Tese (Doutorado em Educação) - Centro de Ciências da Educação, Universidade Federal de Santa Catarina, Florianópolis, 2014.

RIVOLTELLA, Pier Cesare. Piccole scuole: un'ocasione da non perdere. Disponível em: <http://www.piercesare.blogspot. com>. Acesso em: $1^{\circ}$ fev. 2013.

SANTOS, Baoventura de Sousa. Por que as epistemologias do Sul?. Disponível em: <https://www.youtube.com/watch? feature $=$ player_embedded $\& v=E r V G i I U Q H j M>$. Acesso em: $1^{\circ}$ fev. 2013.

SARÀ, Raimondo. Dal mito all'aliscafo: storie di tonni e di tonnare. Migrazioni e biologia, leggende, tradizioni e socialità. Palermo: Arti Grafiche Siciliane, 1998.

WILLIAMS, Raymond. O campo e a cidade: na história e na literatura. São Paulo: Companhia das Letras, 1989.

\section{Notas}

${ }^{1} \mathrm{O}$ presente artigo é um desdobramento da tese de doutoramento da professora Iracema Munarim, trabalho orientado pela professora Gilka Girardello, que contou com a parceria do professor Rogério Santos Pereira em etapas da pesquisa. A referida tese está disponível online e pode ser consultada na íntegra, no repositório da Universidade Federal de Santa Catarina e no site do grupo de pesquisa LaboMidia/UFSC.
2 Estágio realizado pelos pesquisadores Iracema Munarim e Rogério Santos Pereira com o grupo de pesquisa Cremit (Centro di Ricerca sull'Educazione ai Media all'Informazione e alla Tecnologia), na Università Cattolica del Sacro Cuore (Milão), sob supervisão do professor Pier Cesare Rivoltella, com bolsa PDSE/Capes no período de novembro/2011 a junho/2012

${ }^{3}$ Seminario Teniamoci per Mouse 2011, Università degli Studi di Milano Bicocca, Milão, 06/11/2012.

${ }^{4}$ No contexto italiano, tal realidade pode também ser encontrada em algumas comunidades di montagna, como nas escolas situadas na região dos Alpes.

5 Palestra proferida no Seminário Internacional sobre Diversidade Cultural. Brasília, junho de 2007. Disponível em <https://www.youtube.com/ watch?v=U7jo4G4_quQ $>$. Acesso em: 2 mar. 2014.

${ }^{6}$ SANTOS, M. O. Território e sociedade. Entrevista com Milton Santos. 3. ed. Ed. Fundação Perseu Abramo, 2007.

7 Algumas questões que são muito fortes no Brasil, especialmente no que diz respeito a territórios - por exemplo, a questão dos sem-terra -, não estão presentes no contexto italiano.

+ Talvez pela relutância no Brasil de se utilizar o transporte marítimo, não se conseguiu encontrar a tradução da palavra aliscafo para o português, apenas hidrofoil, em inglês. Talvez o mais próximo sejam as "lanchas voadoras" que fazem a travessia Rio-Niterói.

9 A Batalha das Ilhas Egadi (Bataglia delle Isole Egadi) foi um combate naval que deu fim à primeira guerra púnica, entre cartagineses e romanos. Após essa disputa, a região da Sicília foi anexada a Roma.

${ }^{10}$ SARÀ, 1998, p. 12.

${ }^{11}$ Fonte: <http://www.egadivacanze.it/informazioni/favignana/il-museostabilimento-florio.html $>$ ("Il Museo - Ex Stabilimento Florio a Favignana" [S.d.]).

${ }^{12} \mathrm{O}$ programa Profissão Repórter é apresentado pela TV Globo como sendo um espaço experimental de jornalismo televisivo (jovens apresentam as reportagens sob a tutoria de um profissional experiente da emissora, Caco Barcellos). Temos clareza de que programas veiculados na TV Globo, assim como em outras emissoras, são editados e atravessados por interesses econômicos e, por tantas vezes, confundem o jornalismo com o entretenimento e com o espetáculo. No entanto, o assunto abordado pelo programa em questão chamou a atenção por veicular histórias de personagens e lugares que não costumam fazer parte da pauta do telejornalismo nacional. A grande seca que assolou o Nordeste em 2013, por exemplo, pouco foi noticiada no país.

${ }^{13}$ No mesmo movimento de professores e pesquisadores da área da Educação do Campo no Brasil, que questionam a denominação de "classes multisseriadas", preferiu-se utilizar o termo "classes heterogêneas", que leva em consideração a formação de turmas com diferentes idades e aprendizagens, sem necessariamente estarem fechadas em ciclos de seriação, tradicionais na educação.

${ }^{14}$ Texto Piccole scuole: un'ocasione da non perdere, disponível no blog do autor, publicado em 10 de fevereiro de 2013 (RIVOLTELLA, 2013). Disponível em $<\mathrm{http}: / /$ www.piercesare.blogspot.com> . Acesso em: 23 fev. 2014.

${ }^{15}$ Le didattiche tutoriali - em que os alunos têm aulas com professores a distância, mas contam com a presença de tutores presenciais nas escolas (o professor Rivoltella poderá dizer sea afirmação sobre o termo utilizado em seu texto está correta). Ainda não há no Brasil experiências didáticas assim, que já acontecem, por exemplo, nas escolas de zonas rurais da Argentina.

${ }^{16}$ Existem outros projetos governamentais na Itália que incentivam o uso de tecnologias digitais nas escolas, como Isole in Rete e Classe 2.0. Sobre o projeto Classe 2.0 nas Ilhas Egadi, assistir ao vídeo "Favignana Cl@sse 2.0 (em italiano), disponível em <http://www.youtube.com/ watch? $\mathrm{v}=\mathrm{iIqws} 8 \mathrm{klKD} 0>$. Acesso em 3 mar. 2014.

${ }^{17}$ As estratégias de usos das mídias por professores e estudantes da escola de Favignana, inclusive a visita ao cárcere, foram registradas e estão disponíveis em: $<$ http://www.youtube.com/watch?v=OvwKYCyA3uE $>$. Acesso em: 2 mar. 2014.

18 Trata-se da plataforma "VAS - Virtual Art Space", disponível em $<$ http:// www.3dvas.com/>. Acesso em: 5 mar.

${ }^{19} \mathrm{O}$ processo de produção do livro digital pode ser acompanhado no vídeo "Rallo 2.0 - Patrimonio culturale \& web", disponível em $<$ http://www.youtube.com/watch? $\mathrm{v}=\mathrm{FWC} 4 \mathrm{pIt} 3 \mathrm{Wi}$ \& \&list=UUzkv8 4pB2V0k5BCwb6dfCw>. Acesso em: 3 mar. 2014.

${ }^{20}$ No desafio de alfabetizar suas crianças, a Itália convive tanto com aquelas que chegam à escola falando apenas o dialeto aprendido no âmbito 
familiar quanto com a presença crescente de imigrantes de línguas e costumes diversos. Lidar com essa diversidade é um dos desafios da educação contemporânea.

${ }^{21} \mathrm{O}$ desejo de aproximar as crianças do Brasil e da Itália surgiu das inspiradoras conversas que se teve com os educadores das Ilhas Egadi, em especial com a professora Linda Guarino e com o professor Michele Ponzio. De volta ao Brasil, conheceu-se Raquel Dotta Côrrea, professora e pesquisadora que une a sua formação em Letras (italiano) com o interesse pelo uso de tecnologias na educação. Os três autores deste artigo mais a professora Raquel, com o apoio das equipes pedagógicas das escolas, conceberam e estruturaram o projeto. Atualmente, este é coordenado conjuntamente pelas professoras Linda e Raquel e conta com a participação de professores no Brasil e na Itália. Como as duas escolas brasileiras estão localizadas em uma região de grande influência da colonização italiana, as atividades do projeto foram integradas ao ensino da língua italiana que já é oferecido às crianças como uma disciplina curricular de língua estrangeira. Um dos pontos de encontro entre as crianças italianas e brasileiras é o blog construído coletivamente por elas - disponível em <http://brazil-egadi.blogspot.com.br $>$. Acesso em: 4 mar. 2014

Artigo recebido em julho 2014

Aprovado em junho 2015. 